\title{
The role of numerical tests in assessing road restraint system functionality
}

\author{
Marcin Budzynski ${ }^{*}$ (D, Kazimierz Jamroz, Krzysztof Wilde, Wojciech Witkowski, Lukasz Jelinski and Dawid Bruski
}

\begin{abstract}
Key to understanding the needs and building road infrastructure management tools to prevent and mitigate runoff-road accidents is to identify hazards and their sources which are a result of wrong design, construction, and installation of road restraint systems. Building such tools requires advanced studies with field tests, simulations and models to demonstrate the effects of selected parameters on road user safety. The research work included building numerical models which were validated with crash tests and mathematical models to assess the effects of selected parameters on the safety and functionality of devices. Twenty five field tests were the basis for conducting 670 numerical tests. Preliminary results of numerical tests are also presented looking at selected problems such as barriers on curves, presence of kerbs and obstacles within barrier working width. The methodology will help with an optimal selection of parameters leading to improved safety as regards errant vehicles.
\end{abstract}

Keywords: Road safety, Road restraint systems, Roadside, Numerical tests, Crash tests, Road infrastructure

\section{Introduction}

Roadside (hard shoulder, ditch, an area directly adjacent to the road) accidents occur when vehicles run off the road. Because these accidents usually involve hitting a fixed roadside obstacle (tree, utility pole, structure support, culvert front wall, barrier), the majority are quite severe, Budzynski et al. [7]. Approximately $19 \%$ of all people killed in road accidents in Poland died in roadside-related accidents, Budzynski et al. [6]. These include: hitting a tree (a main hazard), hitting a barrier, a utility pole or road sign and vehicle roll-over on an embankment or ditch. A safety barrier is designed to protect people and roadside objects from being hit by an errant vehicle. Barriers help to reduce the consequences of runoff-road accidents for drivers and car occupants.

To ensure the utility of road safety devices, they must operate $24 \mathrm{~h}$ a day and 365 days a year. Continuity means that road safety devices are highly functional and can deliver a high degree of their basic utilities such as road user safety, reliability, ability to maintain and redirect the

\footnotetext{
*Correspondence: mbudz@pg.edu.pl

Department of Civil Engineering and Environment, Gdansk University of Technology, Narutowicza 11/12 Street, 80-233 Gdansk, Poland
}

vehicle, fitness for purpose (functions are ensured despite minor damage), ability to go back to their original functions following a crash, economic effectiveness (reasonable selection) and no negative impact on the environment.

To assess the functionality of road safety barriers, parameters are used to identify: the level of containment, degree of deformation of a vehicle restraint system and the intensity of the incident. While the parameters can be identified in laboratory tests and on-site or simulation tests, there is a shortage of tools for assessing the performance of barrier utility. When barriers are designed, they can only be assessed for how well they perform under standard road and traffic conditions. When barriers are already in operation (and in-the-field inspections are carried out) and have been hit and partly damaged, they can no longer be assessed for their performance. As a result, tools (methods, guidelines) are needed to help with assessing safety barrier functionality under conditions other than standard conditions.

Considering the needs, the objective of the work and analyses described in the article was to define the effects of vehicles striking safety barriers on barrier design (causing damage) and functional parameters. To achieve this goal, the following research questions were formulated:

\section{Springer Open}

(c) The Author(s). 2020 Open Access This article is licensed under a Creative Commons Attribution 4.0 International License, which permits use, sharing, adaptation, distribution and reproduction in any medium or format, as long as you give appropriate credit to the original author(s) and the source, provide a link to the Creative Commons licence, and indicate if changes were made. The images or other third party material in this article are included in the article's Creative Commons licence, unless indicated otherwise in a credit line to the material. If material is not included in the article's Creative Commons licence and your intended use is not permitted by statutory regulation or exceeds the permitted use, you will need to obtain permission directly from the copyright holder. To view a copy of this licence, visit http://creativecommons.org/licenses/by/4.0/. 
1. What factors involved in vehicle movement have a significant effect on those design parameters which define barrier deformation or damage and change barrier functional parameters?

2. Can simple mathematical models be developed to help with estimating the effects of vehicle movement parameters on safety barrier damage and change in functionality?

A safety barrier helps to reduce the effects of out-ofcontrol vehicles leaving the road (by protecting people and roadside objects and by reducing the severity and consequences for those involved in the incident). On the other hand, incidents damage barriers and vehicles.

Unfortunately, safety barriers are not neutral, and may cause accidents, especially if located in the wrong place or featuring incorrect functional parameters. One of the objectives of Road Safety Equipments (RoSE) and Life Cost Analysis of Road Safety Elements" (LifeRoSE) projects (Road Innovation Programme dedicated to national roads) was to identify and analyse factors that affect barrier design parameters and change barrier functionality when hit by a vehicle. Because identifying the effects of all factors on barriers is very difficult, two research methods are used in practice: statistical and mechanistic methods, what the work of Burbridge and Troutbeck [8] presents.

\section{Literature review}

\subsection{Statistical methods}

Statistical methods use available detailed data about dangerous road incidents to extract real cases of vehicles hitting safety barriers. Data are collected about the location of the incident, barrier design conditions, road traffic and other circumstances of the incidents. Next, using the data, mathematical models are built which define the relation between barrier functional parameters and the frequency and scale of vehicle crashes into barriers and of other significant factors. A review of the available research on the effects of roadside on road safety shows that research is largely focused on how selected road parameters (road width, type and width of the hard shoulder, roadside trees and road signs), road structures (bridges, culverts road signs), roadside obstacles (trees, poles) and road equipment (road barriers and fencing) influence run-off-road accident risks, AASHTO [1], Zou and Tarko [36], Holdridge et al. [14], Ambros et al. [2], Jamieson et al. [16], Fitzpatrick [11]. The study results were used to model and simulate the effects of different combinations of road geometric parameters and traffic parameters on accident frequency and consequences, Fitzpatrick [11]. The focus of other research has been on "forgiving" roads which found the clear zone to be very important, AASHTO [1], Norwegian Public Road Administration [25], Jurewicz and Troutbeck [18]. The results of the research were used to inform new guidelines and examples of good practice, Fitzpatrick et al. [11], Ogden [27], La Torre [22]. The RISER project was a key contributor to this, Ridder et al. [9]. It was designed to determine the behaviour of drivers (in adjusting speed) in relation to the conditions encountered. Another project, SAVER, looked at how road safety devices (including safety barriers) are applied across Europe, La Torre et al. [23].

\subsection{Mechanistic methods}

Mechanistic methods use physical relations to calculate barrier functional parameters following a vehicle impact; they help to understand the physical relations (interactions) between vehicles and a safety barrier, Ren and Vasenjak [31]. The most frequently used relations are those between the force with which a vehicle impacts a barrier and vehicle mass, impact speed and impact angle, Sicking and Ross Jr. [32], Ray et al. [29]. The resulting models are applied to single crashes, i.e. a vehicle hitting a specific barrier, and are not usually used to describe the effects of a group of incidents on road sections (in which case the frequency of specific types of incidents is summed up). This approach is used when historical barrier accident data are not available. Mechanistic methods include those that are based on field crash tests (test barriers - TB) and numerical crash tests.

There are a number of tools for assessing the correctness of numerical models using a real crash test, PD CEN/TR 16303 [28]. It is generally considered that results from real crash tests are not questioned and are used to validate numerical models, Goubel et al. [12]. It is important to note, however, that while crash test standards are rigorously observed, not all mistakes can be eliminated: EN 1317 [10], Ray [30].

Many of the works assess numerical models by comparing the Acceleration Severity Index (ASI) and the theoretical head impact velocity (THIV) parameters, Niezgoda et al. [24]. Goubel [12] comparisons are made of vehicle speed charts from numerical calculations and crash test charts. Numerical models can also be assessed based on barrier deformation using a laser scan of a real barrier after impact, Barnat et al. [3] , Kiczko et al. [19]. The LS-Dyna (general-purpose finite element program capable of simulating complex real world problems) instructions for use recommend for the non-physical hourglass energy to be less than $10 \%$ of the highest internal energy, LS-Dyna support [15]. On the other hand, Teng et al. [34] recommends for hourglass energy to not exceed $5 \%$ of total initial energy and be less than $10 \%$ of internal energy at analysis end with total energy change throughout the entire analysis to not exceed $10 \%$. Total energy is defined by the authors as the sum of kinetic energy, potential energy and contact. In the RoSE and LifeRoSE projects vehicle crashes against elements of safety barriers 
and other road safety devices are simulated using finite element method (FEM), Kleiber [21]. The world's basic and recognised tool for generating and solving non-linear equations of vehicle-barrier movement upon impact is the commercially available system LS-Dyna. Compared with other FEM codes, LS-Dyna is primarily designed to calculate and analyse so called fast dynamic phenomena (problems of wave propagation) where the corresponding wavelengths are of the order or much lower than the characteristic acoustic wavelengths, Hallquist [13].

Klasztorny et al. [20], analysed a road barrier SP-05/2, class N2-W4-A reinforced with a composite and foam overlay with rubber pads. Nycz [26] gives a simplified description of modelling a bus in a crash test TB51. A comparison of the parameters suggests that the simplified model performs well. The impact on car occupants was defined in test TB11 with TB42 used to identify barrier working width. Teng et al. [34] presents a study into a concrete barrier hit by a vehicle with a mass of $900 \mathrm{~kg}$ and a speed of $100 \mathrm{~km} / \mathrm{h}$. Computer simulations can also be used to assess innovative types of safety barriers.

In a series of publications of Borkowski et al. [5], Jamroz et al. [17], the authors studied buses impacting with bridge parapets (standard test TB51). The numerical model was validated and a detailed analysis was conducted of the forces in post anchors. Wilde et al. [35] analyses the links between ASI and THIV and car occupant injury indices. Sturt and Fell [33] and Bielenberg et al. [4] presents the design process (supported with numerical simulations) and results of real crash tests looking at the links between the concrete barrier and steel barrier.

RoSE and LifeRoSE projects are innovative in that they address a broader range and diversity of analyses. Compared to other research projects, including those listed above, this study covers an extended scope of factors which affect barrier functionality. The results add to the existing knowledge of road restraint system design and application.

\section{Study method}

\subsection{Field crash tests characteristics}

\subsubsection{Scope of available data}

A report was written for each field crash test providing the following data: type of test (in the field, simulation), detailed characteristics of the test, barrier data (e.g. type, barrier width, post spacing), vehicle data (type, mass, impact speed and impact angle and speed and angle of departure), barrier parameters after impact (normalised working width, dynamic deflection, maximal sustained deformation, length of contact between vehicle and barrier, length of barrier damage, number of barrier segments that need replacing, number of damaged posts, incident severity indices (ASI, THIV), video and photographic documentation (field tests), comments and drawings for specific results such as barrier intrusion (numerical tests).

\subsubsection{Set of field crash tests}

A set of 25 tests was analysed combining LifeRoSE (3 tests), RoSE (9 tests) and barrier manufacturers' tests (13 tests). Tests carried out under RoSE and LifeRoSE include: TB32 (vehicle with a mass of $1500 \mathrm{~kg}$, impact speed $110 \mathrm{~km} / \mathrm{h}$, impact angle $20^{\circ}$ ) for a road wire rope barrier for a section of a barrier installed on a curve with a radius of $400 \mathrm{~m}$ (two impacts), TB32 for a road steel barrier for a section of a barrier installed on a horizontal curve with a radius of $400 \mathrm{~m}$ (two impacts), TB11 (vehicle with a mass of $900 \mathrm{~kg}$, impact speed $100 \mathrm{~km} / \mathrm{h}$, impact angle $20^{\circ}$ ) for a bridge barrier with a kerb $14 \mathrm{~cm}$ high (two impacts), TB51 (vehicle with a mass of 13,000 $\mathrm{kg}$, impact speed $70 \mathrm{~km} / \mathrm{h}$, impact angle $20^{\circ}$ ) for a bridge barrier with a kerb $14 \mathrm{~cm}$ high, TB32 for the connection between a road wire rope barrier with a steel barrier, TB51 for a road steel barrier and a lighting pole placed within the barrier's working width, TB41 (vehicle with a mass of $10,000 \mathrm{~kg}$, impact speed $70 \mathrm{~km} / \mathrm{h}$, impact angle $8^{\circ}$ ) for a concrete barrier, TB32 for a road wire rope barrier (impact angle $7^{\circ}$ ), TB32 for a road steel barrier (impact angle $7^{\circ}$ ), see Fig. 1 .

For the purposes of the analysis, a set of numerical tests was used simulating vehicle impact with barriers. The set comprised 570 tests conducted under this LifeRoSE project (173 numerical tests) and RoSE project (397 numerical tests) totalling 139 numerical tests with a concrete barrier, 149 numerical tests with wire rope barrier and 282 numerical tests with steel barrier.

\subsection{Numerical tests characteristics}

The main objective of safety barrier modelling and simulation tests is to develop numerical models of crash tests. The work conducted in 2016 included an extensive review of the literature, adjusting vehicle numerical models to the needs of the project and preliminary numerical tests. Building on these results in 2017 further research included simulations of virtual crash tests using a commercial system of the FEM, the LS-Dyna. LS-Dyna is a well-known and widely used commercial FEM code, designed to deal with highly nonlinear, short lasting phenomena. In the presented research, explicit dynamics solver is used, due to its robustness in solving problems with a very large number of degrees of freedom, many material laws included and possible complex contact behaviour. Another advantage of LS-Dyna is parallelization, which makes calculations scalable up to hundreds of cores. Nevertheless, an explicit dynamics algorithm is conditionally stable. It means that the time step in calculations should be very small and it is dependent, among others, on the characteristic size of the finite element. Furthermore, the time step size must be a compromise between the total calculation time and the level of details in the model. In a typical LS-Dyna model, beside geometrical data, dozens of materials definitions are included, with 

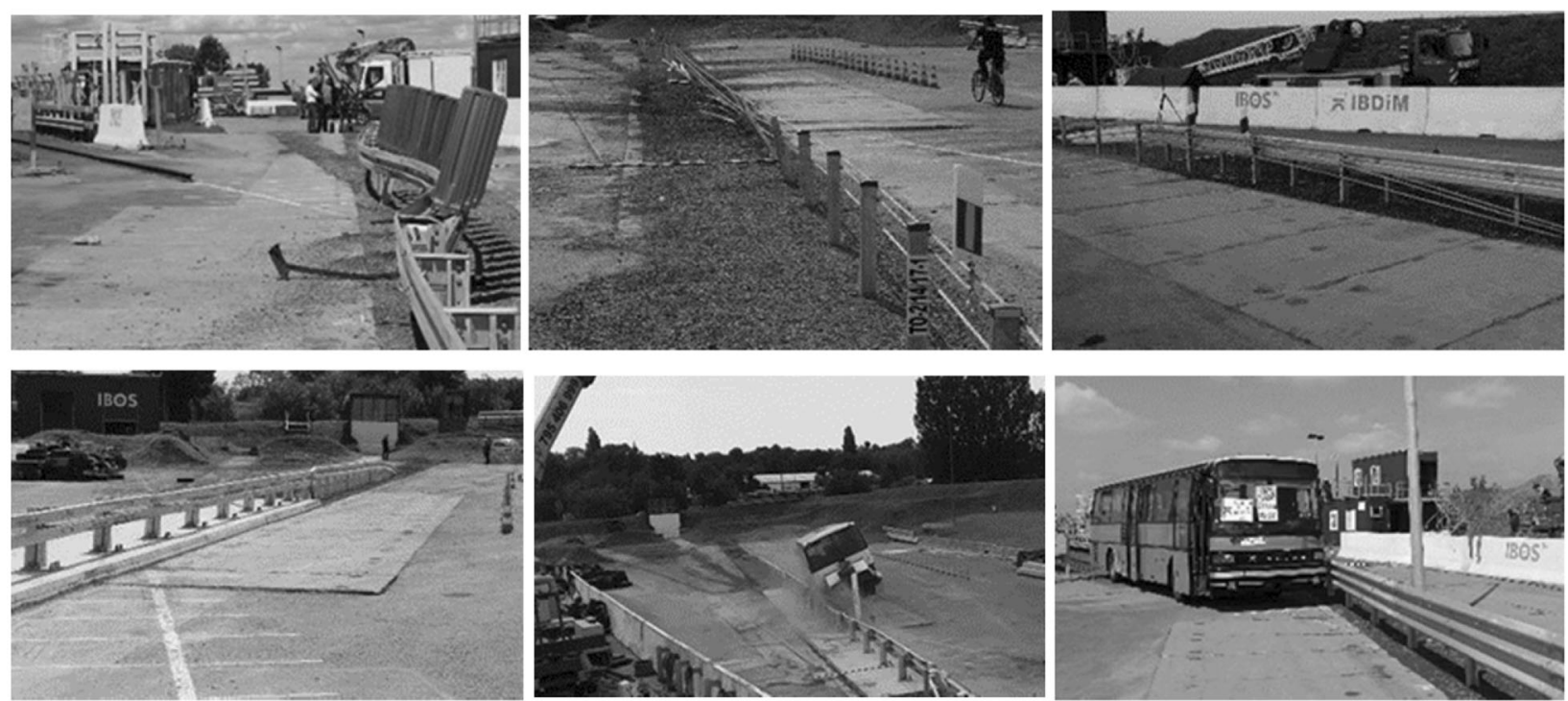

Fig. 1 Photographic crash test documentation, source: the authors

hundreds of parameters defined. Some of them ale collected from laboratory tests, some of them are prescribed basing on research papers, some of them are defined according to common engineering knowledge. This causes the fact that numerical analysis must be conducted by an experienced research team, with great knowledge of FEM and material laws theory and their implementation. Huge amount of post-processing data must be carefully revised to prove lack of numerical issues, like non-physical penetrations, so called "shooting nodes" or hourglass deformations.

A reliable simulation may be a basis for extended parametric analyses with changing conditions such as the initial conditions (vehicle speed and impact angle). This, however, should be treated with some caution with the results tested each time for reliability and any possible numeric errors. The experience of project participants which they gained by consulting constructors who conduct simulations for barrier manufacturers, shows that the process, although reverse to validation (i.e. anticipating actual behaviour based on numerical simulation, see Fig. 2), is correct and reliable.

Even the most detailed of models is of no value unless its results are compared to a real test. Numerical solutions must be confronted with site test results in a qualitative and quantitative check. This process validates a solution. To ensure that barrier validation was performed properly, the numerical simulation should be consistent with the site test in the following points: maintaining the vehicle on the lane, vehicle rollover, maintaining the vehicle within the so called exit box, wheel trajectories, damage to vehicle suspension, damage to barrier longitudinal elements (guardrails), barrier dynamic deflection, vehicle intrusion, intrusion of parts of barrier into the vehicle, deformation of the entire object of study.

As barrier fragments are being damaged, the sequence of this should be the same in the site test and simulation. The reliability of numerical tests is defined by criteria of a quantitative comparison of the parameters:

- dynamic deflection: $\mid \mathrm{DM}_{\text {crash test }}-\mathrm{DM}_{\text {numerical }}$ test $\mid \leq 0,05 \mathrm{~m}+0,1 \mathrm{DM}_{\text {crash tests }}$,

- working width: $\left|\mathrm{WW}_{\text {crash test }}-\mathrm{WW}_{\text {numerical test }}\right| \leq$ $0,05 m+0,1 W W_{\text {crash tests }}$

- intrusions: $\left|W_{\text {crash test }}-W_{\text {numerical test }}\right| \leq 0,05 \mathrm{~m}+$ $0,1 W_{\text {crash tests, }}$

- ASI: $\left|\mathrm{ASI}_{\text {crash test }}-\mathrm{ASI}_{\text {numerical test }}\right| \leq 0,1$,

- THIV: $\mid$ THIV $_{\text {crash test }}-$ THIV $_{\text {numerical test }} \mid \leq 3 \mathrm{~km} / \mathrm{h}$.

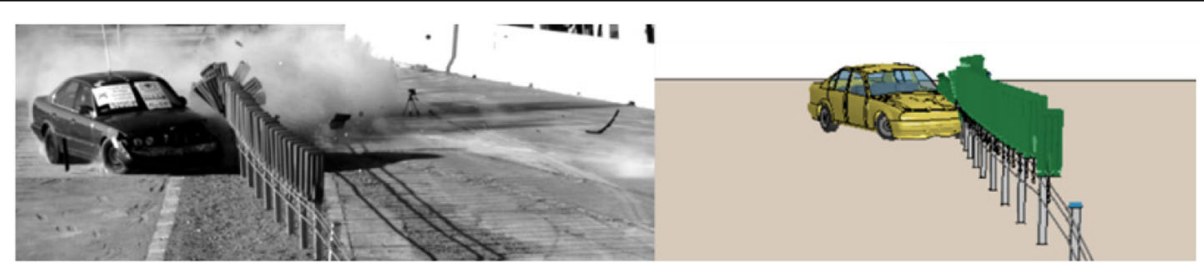

Fig. 2 Example of validation crash test 
In each case, the difference between the simulation and site test moment reaching their maximum values cannot be greater than $0.05 \mathrm{~s}$.

Figure 3 shows the standard test TB32. A passenger car $\left(1500 \mathrm{~kg}, 110 \mathrm{~km} / \mathrm{h}, 20^{\circ}\right.$ angle) hits a W-beam steel barrier. The collision (length of contact, vehicle redirection) and functional parameters (ASI, THIV, working width) were represented reliably. Figure 4 shows the passenger car crash $(1500 \mathrm{~kg})$ in a non-standard test $(110$ $\mathrm{km} / \mathrm{h}$, impact angle $50^{\circ}$ ). In this case, with no field test results, it is advisable to thoroughly check the simulation for non-physical phenomena (such as element overlay, "glued" contact surface).

Figure 5 shows the result of a bus hitting $(13,000 \mathrm{~kg})$ a concrete barrier. Major destruction to parts of the concrete are clearly visible. In reality, while concrete may no longer be able to redirect loads, it continues to retain a specific volume. In the simulation, a "vanishing' effect was observed with extensive parts of the structure gone which allowed the vehicle's intrusion into the barrier. In this case, further and more in-depth studies into structural effort are required.

About $10 \%$ of the numerical tests involved two specific effects of vehicles hitting a barrier: the vehicle was wedged or immobilised under the barrier, the barrier was broken through or the vehicle went under or over the barrier). Both cases occur primarily when the vehicle hits a segment of the barrier at a high angle or with very high kinetic energy (Fig. 6).

As defined in the objective, the tests selected were designed to help to:

1. Identify the most relevant factors of vehicle movement that have an effect on barrier deformation or destruction and change barrier functional parameters;

2. Develop simple mathematical models to estimate the effects of barrier design parameters and vehicle movement parameters on the extent of damage and change in barrier functionalities.

\section{Results}

\subsection{Identifying the factors}

A vehicle leaving the road and hitting a barrier damages or destroys it. As shown from the analysis of site tests, the extent of barrier deformation or damage and change in functional parameters depends largely on two components:

- the kinetic energy of a vehicle hitting a safety barrier,

- the resistance to impact, i.e. those design features of a safety barrier that help it to resist the force generated by the vehicle hitting the barrier and absorb the vehicle's kinetic energy.

The lateral kinetic energy of a vehicle hitting a safety barrier EKL depends on the vehicle's mass MP, speed on impact VP and angle of impact KU. Lateral kinetic energy EKL of the vehicle hitting a safety barrier is defined using this formula (1):

$$
E K L=\frac{M P \cdot(V P \cdot \sin (K U))^{2}}{2}
$$

Symbols: EKL - vehicle lateral (side) kinetic energy $(\mathrm{kJ}), \mathrm{MP}$ - vehicle mass $(\mathrm{kg}), \mathrm{VP}$ - the speed of vehicle impact on the barrier $(\mathrm{m} / \mathrm{s}), K U$ - angle of vehicle impact on the barrier (degrees), DM - dynamic deflection of barrier after vehicle impact (m), K - safety barrier stiffness $(\mathrm{kN} / \mathrm{m}, \mathrm{kJ} / \mathrm{m} 2)$.

Figure 7 shows the relationship between lateral kinetic energy EKL of a vehicle hitting a barrier and vehicle mass MP and angle of impact KU. This is overlaid with the results of simulation and site tests. The results confirm the significance of the factors identified in the relationship (1). The resistance of safety barriers to deformation caused by vehicle impact can be measured using parameters such as: barrier stiffness $\mathrm{K}$ and barrier dynamic deflection DM. The stiffness of barrier design $\mathrm{K}$

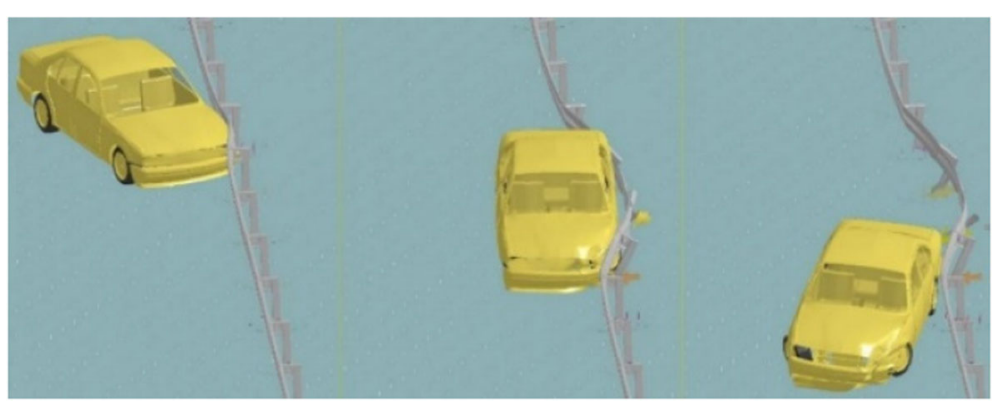

Fig. 3 Steel barrier, car $1500 \mathrm{~kg}$ 


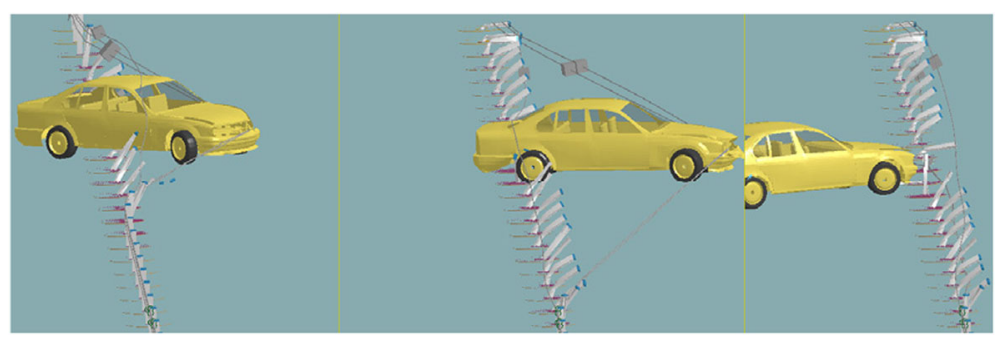

Fig. 4 Car $1500 \mathrm{~kg}, 110 \mathrm{~km} / \mathrm{h}$, impact angle $50^{\circ}$

can be estimated as the quotient of the force which characterises the vehicle hitting the barrier and the distance over which the barrier was displaced as a result of being hit by the vehicle. Because energy is the product of force and distance, barrier stiffness (as the force of resistance) is the quotient of the energy of the striking vehicle per unit of displacement. Safety barrier stiffness K may be defined using the formula (2):

$$
K=\frac{2 \cdot E K L}{D M^{2}}=\frac{M P \cdot(V P \cdot \sin (K U))^{2}}{D M^{2}}
$$

Figure 8 shows the relationship between barrier dynamic deflection DM and barrier stiffness $K$ and lateral kinetic energy of the vehicle striking the barrier EKL. As can be seen in the diagram, barrier dynamic deflection DM which characterises the standard barrier design parameters increases as the vehicle's lateral kinetic energy EKL and its most important component which is the lateral speed of the vehicle striking the barrier VPL go up. It decreases as barrier stiffness $\mathrm{K}$ goes up. The results confirm the significance of the factors identified in the relationship (2).

As can be seen in the diagram, barrier dynamic deflection DM which characterises the standard barrier design parameters increases as the vehicle's lateral kinetic energy EKL and its most important component which is the lateral speed of the vehicle striking the barrier VPL go up. It decreases as barrier stiffness $\mathrm{K}$ goes up. The results confirm the significance of the factors identified in the relationship (2). Type of safety barrier, its dynamic deflection DM and vehicle mass MP also have an effect on barrier damage LU when it is hit by a vehicle as shown in Fig. 9.

Driver and car occupant safety is one of the functionality features of road safety barriers. The more rigid the barrier, the higher the risk of becoming a casualty (injury or death) of a road user who is in the vehicle as it strikes the barrier. Road user (drivers and vehicle occupants) safety in vehicles hitting a barrier is measured with the Acceleration Severity Index (ASI). ASI depends on the type of safety barrier, primarily its stiffness $K$, and speed on impact VPL. As safety barrier stiffness $K$ and vehicle lateral speed VPL increase, so does the ASI. An increase in barrier flexibility to vehicle impacts measured with dynamic deflection DM helps to reduce the ASI, i.e. to reduce the severity of barrier crashes as shown in Fig. 10.

To ensure that barriers are resistant to impacts and that drivers and car occupants are safe while in a vehicle hitting a barrier, a compromise must be reached in designing barriers, which is a challenge for barrier designers.

\subsection{Modelling attempts}

Using the set of data from site and simulation tests and specialist statistical programmes (STATISTICA), an attempt was made to develop mathematical models for a few selected cases. The model of the relationships of the lateral kinetic energy of a vehicle hitting a barrier EKL when the barrier is penetrated or the

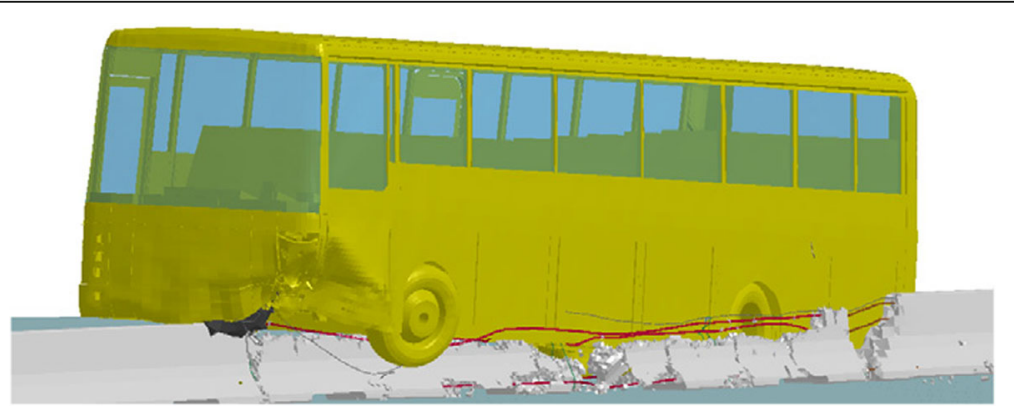

Fig. 5 Concrete barrier, bus $13 \mathrm{t}, 80 \mathrm{~km} / \mathrm{h}, 30^{\circ}$ 


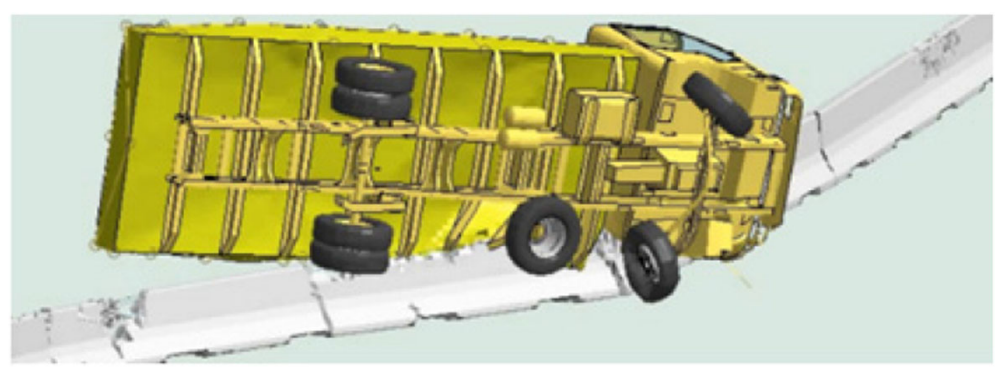

Fig. 6 Vehicle breaks through a barrier during a simulation test

vehicle is wedged underneath the barrier is described with the following formula (3):

$$
\mathrm{EKL}_{\mathrm{s} 1}=\mathrm{MP}^{0,371} \cdot \exp (0,174 \cdot \mathrm{KU}+2,185)
$$

The relationships in Fig. 7 show that vehicle energy EKL needed to penetrate the barrier or for the vehicle to become wedged underneath depends mainly on vehicle mass MP and angle of impact KU. The results were analysed and showed that for normal stiffness barriers, barrier penetration or wedging are very likely, if kinetic energy is close to or greater than $200 \mathrm{~kJ}$ or if the angle of impact KAT is greater than 20 degrees. Figure 11 shows an example.

The model of the relationships of dynamic deflection DM when a barrier is hit by a vehicle is described with the following formula (6):

$$
\mathrm{DM}=4,69 \cdot \mathrm{K}^{-0,5} \cdot \exp (0,0011 \cdot \mathrm{EKL}-0,00014 \cdot \mathrm{MP})
$$

The relationships in Fig. 8 show that barrier dynamic deflection DM depends on barrier stiffness K, the energy of the impact EKL and type of vehicle (vehicle mass
MP). There was also an attempt to develop models of the relationship between length of damage LU and dynamic deflection DM and vehicle mass MP (formula 5) and barrier stiffness $K$ and lateral speed of the vehicle striking the barrier VPL (formula 6).

$$
L U_{1}=0,433 \cdot\left(\frac{D M}{\sin K U}\right) 2,582+7,752 \cdot \exp \left(0,102 \cdot \frac{M P}{1000}\right)
$$

$$
\mathrm{LU}_{2}=29,29 \cdot \mathrm{K}^{-0,362} \cdot \mathrm{VPL}^{0,158}
$$

Analysis of selected results for a steel barrier shows that length of damage $\mathrm{LU}$ increases along with a growing dynamic deflection DM and lateral speed of the vehicle striking the barrier VPL. There was also an attempt to develop models of the relationship between crash severity rate ASI and dynamic deflection DM and lateral speed VPL (formula 7) and barrier stiffness $\mathrm{K}$ and lateral speed of a vehicle hitting a barrier VPL (formula 8).

$$
\mathrm{ASI}_{1}=0,057 \cdot \mathrm{DM}^{0,320} \cdot \mathrm{VPL}^{1,132}
$$

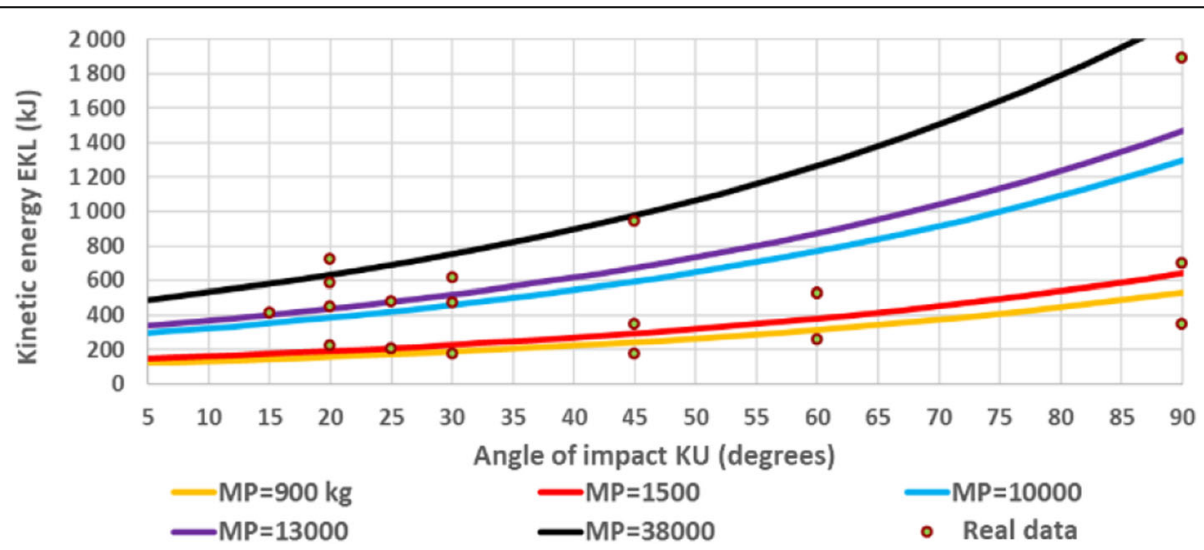

Fig. 7 Relationship between lateral kinetic energy EKL of a vehicle hitting a barrier and vehicle mass MP and angle of impact KU overlaid with the results of simulation and site tests 


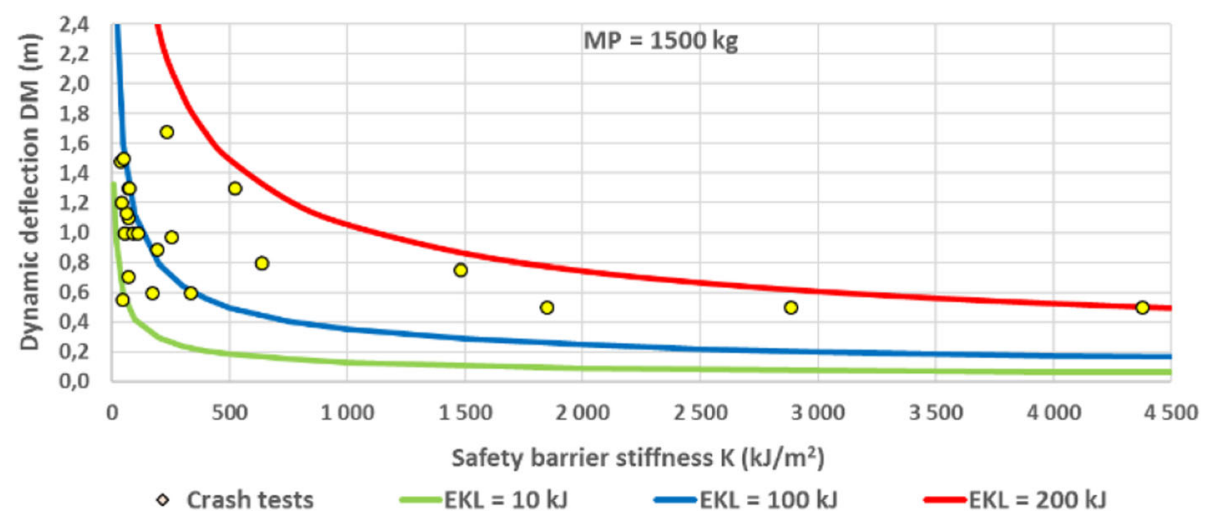

Fig. 8 Relationship between barrier dynamic deflection DM and barrier stiffness $\mathrm{K}$ and lateral kinetic energy of the vehicle striking the barrier EKL overlaid with the results of site tests and simulation

$$
\mathrm{ASI}_{2}=0,048 \cdot \mathrm{K}^{0,165} \cdot \mathrm{VPL}^{0,857}
$$

Analysis of selected results for a steel barrier (Fig. 10) shows that ASI numerical value increases along a growing barrier stiffness (and a decrease in dynamic deflection DM) and lateral speed of a vehicle hitting a barrier VPL. With a limited number of simulation tests used for the analyses, caution is advised as to how the models should be interpreted, especially in the boundary ranges of independent variables.

\section{Discussion of the results}

The study (tests) and numerical tests and analysis of the results helped to answer the research questions. The work shows that the basic design parameters (barrier working width, dynamic deflection) and functional parameters (accident severity) depend on two basic factors: the kinetic energy of a vehicle hitting a barrier (and mainly its lateral component) and the barrier's designed resistance to impact (stiffness and barrier flexibility). Based on an analysis of the results, we can see that:

- the extent of damage to barriers depends significantly on the type of barrier and its design parameters such as: stiffness $\mathrm{K}$ or barrier flexibility measured with dynamic deflection DM, a higher barrier stiffness reduces the length of damage to barrier LU, and a higher barrier flexibility (dynamic deflection DM) increases the length of the damage LU,

- clarity (based on the study so far) is needed as regards the effect of the kinetic energy of a striking vehicle on the extent of barrier damage; as lateral kinetic energy increases: the extent of damage to steel and rope barriers is reduced while concrete barriers suffer more damage,

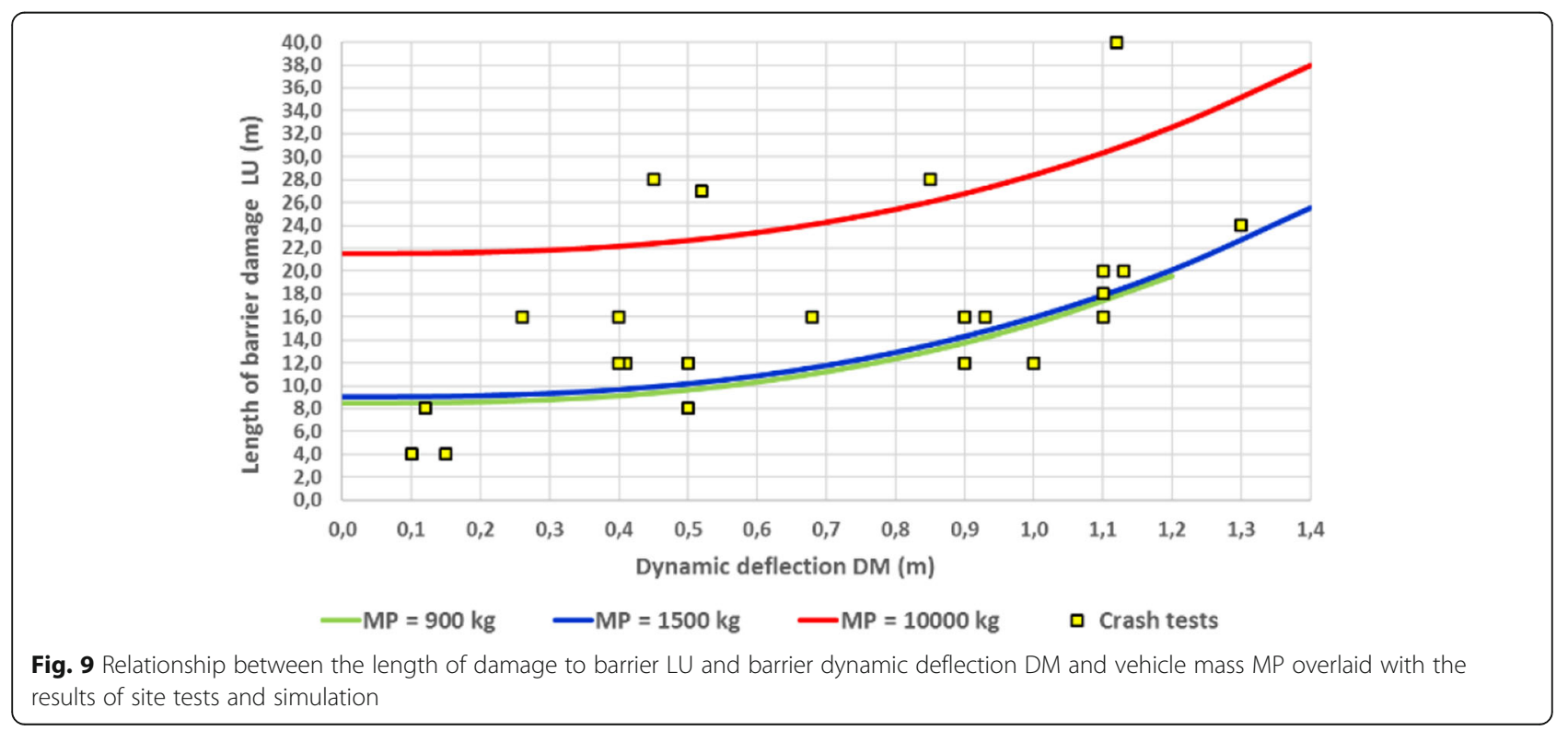




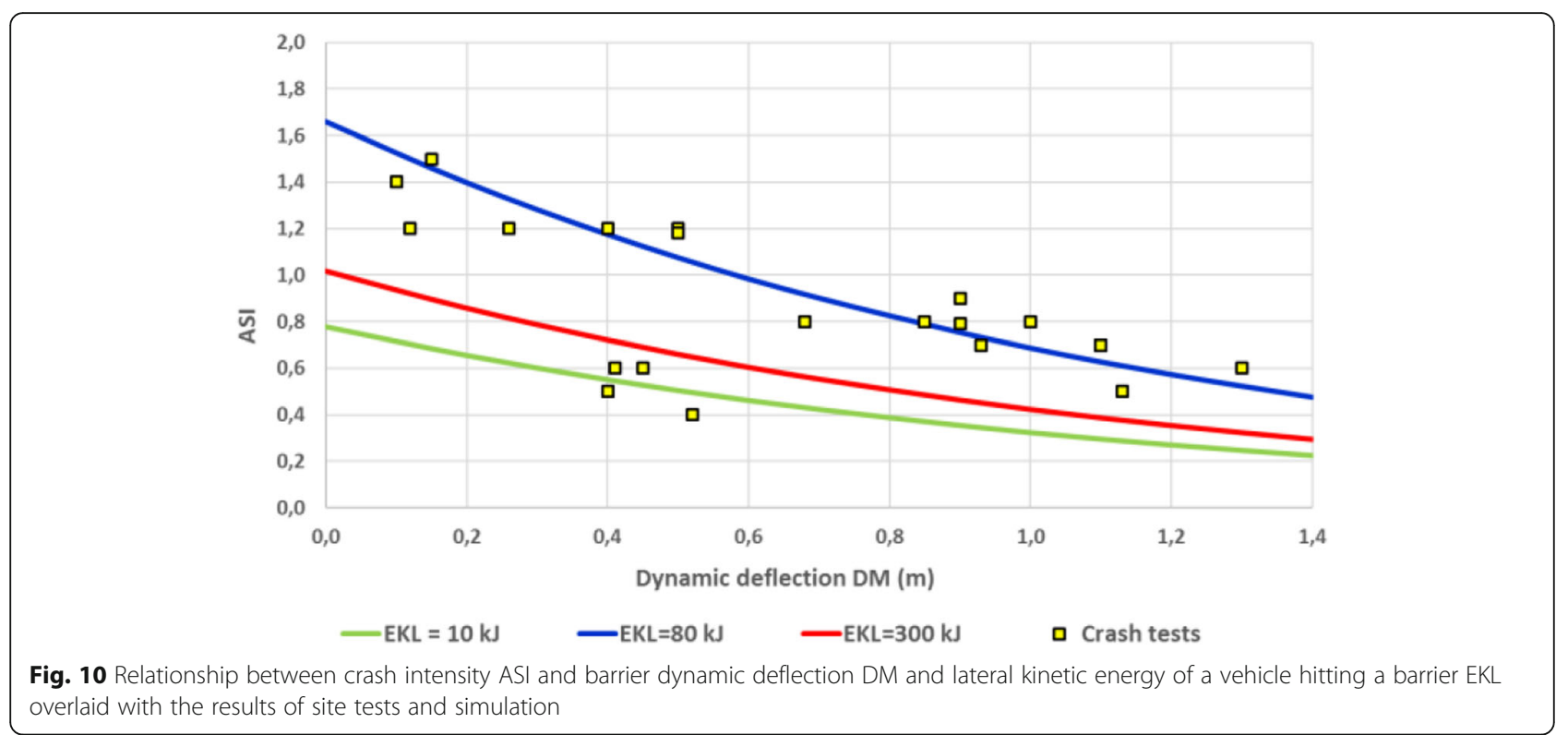

- in the case of normal stiffness barriers, barrier penetration or vehicle wedging underneath is very likely when kinetic energy is close to or greater than $200 \mathrm{~kJ}$ or when the angle of impact is higher than 20 degrees,

- the severity of accidents ASI caused by vehicles striking a barrier is significantly affected by the type of safety barrier, and primarily by its stiffness and the energy of the vehicle striking the barrier.

The analyses and available data from simulation tests have helped to draw up descriptive models of the relationships between design parameters (barrier working width, dynamic deflection) and functional parameters (accident severity) and the most significant factors. But because only a limited number of simulation tests are available, a more cautious interpretation of the models is advised, especially for the boundary ranges of independent variables. New research in the future should include a wider set of numerical tests and a wider range of parameters.

\section{Conclusion}

Based on the Finite Element Method, numerical simulations of crash tests can be a reliable source of information about road safety devices, vehicle behaviour and the overloads affecting vehicle occupants. If correctly verified, numerical tests can significantly aid the design and modification of existing safety barriers. The benefit they offer is the ability to analyse many different configurations of the devices, their locations and different driving conditions where real tests would be very difficult or impossible. $\mathrm{Nu}$ merical simulations give a unique insight into the mechanisms that occur during the dynamic and fast changing process which is a vehicle striking a road safety device. Thanks to numerical calculations, it is possible to study indepth how structures deform. As a result, we can get a better understanding of how safety devices work on roads. Today, because access to powerful computations is easy, it is possible to carry out a high number of simulations. It should be noted, however, that a responsible use of numerical calculations in the area of road safety requires knowledge and experience and the results have to go through a thorough scrutiny to eliminate mistakes. Despite the limitations, numerical tests of vehicles striking a barrier are fairly frequently applied today to test the functionality of the devices. Simulations go a long way towards reducing the number of costly crash tests. The numerical tests have

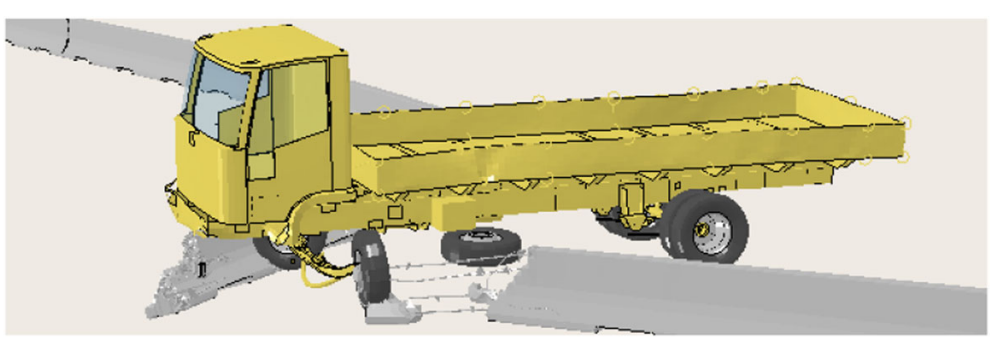

Fig. 11 Example of a numerical test involving a heavy goods vehicle penetrating a barrier 
helped to identify the most significant design and movement factors that influence the operation and damage to safety barriers. The results of the tests have helped to build mathematical models making analysis of safety barriers possible under different and non-normative conditions. The results of the research will also be used to develop new guidelines for the design and maintenance of safety barriers. Thanks to the guidelines, it will be possible to shape a safe road infrastructure and eliminate the most frequent mistakes. There are plans to develop and extend the scope of numerical tests of safety barriers and the results will be presented in upcoming articles.

\section{Acknowledgements}

Research is funded by the Development of Road Innovation research programs, project RID3A and RID3B (contract number DZP/RID-I-67/13/ NCBR/2016 and DZP/RID-I- 67/12/NCBR/2016), and commissioned by The National Centre for Research and Development (NCBiR) and the General Directorate for National Roads and Motorways (GDDKiA).

ETRR is aimed at a readership including researchers, practitioners in the design and operation of transportation systems, and policymakers. ETRR aims to disseminate and discuss new ideas and methodologies that originate in, or are of special interest to, the European transport research community. The research presented in the article concerns a very important element of road equipment, which are road restraint systems. The quality of the presented research is related to their scope. They apply to all types of barriers, more than 600 numerical tests are based on more than 20 field tests. The obtained results will enable the implementation of safer solutions in the area of road infrastructure design. The results obtained will be useful for designers, scientists, or groups to which papers in ETRR are addressed.

\section{Authors' contributions}

MB prepared a draft of the manuscript, prepared a part of the literature review, described field crash tests and conclusions. $K J$ and $L J$ developed models regarding road barrier parameters. KW, WW and DB prepared a part of the literature review and prepared drawings from numerical tests. All authors read and approved the final manuscript.

\section{Availability of data and materials}

The datasets used and analysed during the current study are available from the corresponding author on reasonable request.

\section{Consent for publication}

The authors declare that the content of the manuscript has not been published, or submitted for publication elsewhere.

Special issue: 8th Transport Research Arena TRA 2020, April 27-30, 2020, Helsinki, Finland.

\section{Competing interests}

The authors declare that they have no competing interests.

Received: 5 July 2019 Accepted: 29 April 2020

Published online: 09 May 2020

\section{References}

1. AASHTO, Roadside Design Guide. 2011.

2. Ambros, J., Havranek, P., Valentova, V., Krivankova, Z., \& Striegler, R. (2016). Identification of hazardous locations in regional road network Comparison of reactive and proactive approaches. Transport Research Procedia, 14, 4209-4217.

3. Barnat, W., Bogusz, P., Dziewulski, P., Gieleta, R., Kiczko, A., Klasztorny, M., Niezgoda, T., \& Ochelski, S. (2010). Experimental validation of the numerical model of a car impact on a road barrier. Journal of KONES Powertrain and Transport, 17(1), 17-27.

4. Bielenberg, R. W., Gutierrez, D., Faller, R. K., Reid, J. D., \& Tenhulzen, P. (2017). Development of a test level 3 transition between guardrail and portable concrete barriers. Transportation Research Record Journal of the Transportation Research Board, No. 2638, pp. 77-87.
5. Borkowski, W., Hryciow, Z., Rybak, P., Wysocki, J., \& Wisniewski, A. (2014). Studies on the effectiveness of the innovative road safety system. Journal of KONES Powertrain and Transport, 21, 2.

6. Budzynski, M., Jamroz, K., \& Jelinski, Ł. (2018). Assessment of Road Restraint Systems in Polish Conditions. Journal of KONBiN, 45(1), 325-343.

7. Budzynski, M., Jamroz, K., Jelinski, L., Antoniuk, M. (2016). Why are trees still such a Major Hazard to drivers in Poland? Transport research arena 2016. Transportation Research Procedia.

8. Burbridge, A., Troutbeck, R. (2016). Measuring the residual risk associated with road safety barriers. Roadside Safety Design and Devices: International Workshop [Transportation Research Circular, Number E-C215]. U.S. National Research Council, Transportation Research Board, United States of America, pp. 38-49.

9. De Ridder, S., Van Der Horst, R., Naing, C., \& Thomson, R. (2006). Identify envelope of vehicle and driver response prior to collisions. Project RISER, European Community.

10. EN 1317-2:2010. Road restraint systems - Part 2: Performance classes, impact tests acceptance criteria and test methods for safety barriers including vehicle parapets.

11. Fitzpatrick, C. D., Harrington, C. P., Knodler, M. A., \& Romoser, M. R. E. (2014). The influence of clear zone size and roadside vegetation on driver behaviour. Journal of Safety Research, 49, 97-104.

12. Goubel, C., Di Pasquale, E., Massenzio, M., \& Ronel, S. (2009). Comparison of crash tests and simulations for various vehicle restraint systems. 7th European LS-DYNA Conference. Salzburg: DYNAmore GmbH, pp. 1-12.

13. Hallquist, J. O. (2006). LS-DYNA theory manual. Livermore: Livermore Software Technology Corporation (LSTC).

14. Holdridge, J. M., Shankar, V. N., \& Ulfarsson, G. F. (2005). The crash severity impacts of fixed roadside objects. J Saf Res, 36(2), 139-147.

15. LS-Dyna Support. Hourglass. http://www.dynasupport.com/howtos/ element/hourglass. Accessed 13 June 2016

16. Jamieson, N., Waibl, G., Davies, R. (2013). Use of roadside barriers versus clear zones. NZ Transport Agency research report 517. Wellington: NZ Transport Agency.

17. Jamroz, K., Burzynski, S., Witkowski, W., \& Wilde, K. (2015). Numerical methods for the assessment of bridge safety barriers. In M. Kleiber et al. (Eds.), Advances in Mechanics: Theoretical, Computational and Interdisciplinary Issues. Gdansk: Taylor and Francis Group.

18. Jurewicz, C., \& Troutbeck, R. A. (2012). Safe system-based approach to selection of clear zones, safety barriers and other roadside treatments, Australas. Road Safety Research Policy Education Conference, 4-6.

19. Kiczko, A., Niezgoda, T., Nowak, J., \& Dziewulski, P. (2010). Numerical implementation of car impact into the modified road barrier. Journal of KONES Powertrain and Transport, 17(3), 189-196.

20. Klasztorny, M., Zielonka, K., Nycz, D. B., Posuniak, P., \& Romanowski, R. K. (2018). Experimental validation of simulated TB32 crash tests for SP-05/2 barrier on horizontal concave arc without and with composite overlay. Archives of Civil and Mechanical Eng, 18, 339-355.

21. Kleiber, M. (1998). Handbook of computational solid mechanics. Berlin: Springer-Verlag.

22. La Torre, F. (2012). Forgiving Roadsides Design Guide. Conference of European Directors of Roads CEDR.

23. La Torre, F., Erginbas, C., Thomson, R., Amato, G., Pengal, B., Stefan, C., \& Hemmings, G. (2016). Selection of the Most appropriate roadside vehicle restraint system - The SAVeRS project.

24. Niezgoda, T., Barnat, W., Dziewulski, P., \& Kiczko, A. (2012). Numerical modelling and simulation of road crash tests with the use of advanced CAD/CAE systems. Journal of KONBiN, 3(23), 95-108.

25. Norwegian Public Roads Administration. (2014). Vehicle restraint systems and roadside areas. NPRA Directorate of Public Roads. https://www.vegvesen. no/_attachment/393502/binary/968120?fast_title=Manual+N101E+Vehicle+ Restraint+Systems+and+Roadside+Areas.pdf.

26. Nycz, D. B. (2018). Comparison of functionality of type $a$ and b guide rails of steel road safety barriers. The Baltic Journal of Road and Bridge Engineering, 13(3).

27. Ogden, K. W. (1996). Safer roads: A guide to road safety engineering. Avebury Technical.

28. PD CEN/TR 16303. (2012). Road restraint systems - Guidelines for computational mechanics of crash testing against vehicle restraint system.

29. Ray, M. H., Asce, M., Silvestri, C., Conron, C. E., \& Mongiardini, M. (2009). Experience with cable median barriers in the United States: Design standards, policies, and performance. J Transp Eng, 135(10) 
30. Ray, M. H. (1996). Repeatability of full-scale crash tests and criteria for validating simulation results. Transportation Research Record, Vol, 1528, $155-160$.

31. Ren, Z., \& Vesenjak, M. (2005). Computational and experimental crash analysis of the road safety barrier. Eng Fail Anal, 12, 963-973.

32. Sicking, D. L., \& Ross Jr., H. Y. E. (1986). Benefit-cost analysis of roadside safety alternatives. Transp Res Rec, 1065, 98-105

33. Sturt, R., \& Fell, C. H. (2012). The influence of ASI on injury risk in impacts with roadside safety barriers, CROW Infradagen.

34. Teng, T., Liang, C., \& Tran, T. (2015). Effect of various W-beam guardrail post spacing and rail heights on safety performance. Advances in Mechanical Engineering, 7, 11.

35. Wilde, K., Jamroz, K., Bruski, D., Burzynski, S., Chroscielewski, J., Witkowski, W. (2016). Numerical tests of a bus collision in a barrier and truss support structure. JCEEA, t. XXXIII, z. 63 (1///16), p. 455-467.

36. Zou, Y., \& Tarko, A. P. (2018). Barrier-relevant crash modification factors and average costs of crashes on arterial roads in Indiana. Accid Anal Prev, 111, 71-85.

\section{Publisher's Note}

Springer Nature remains neutral with regard to jurisdictional claims in published maps and institutional affiliations.

\section{Submit your manuscript to a SpringerOpen ${ }^{\circ}$ journal and benefit from:}

- Convenient online submission

- Rigorous peer review

- Open access: articles freely available online

- High visibility within the field

- Retaining the copyright to your article

Submit your next manuscript at $\boldsymbol{\nabla}$ springeropen.com 